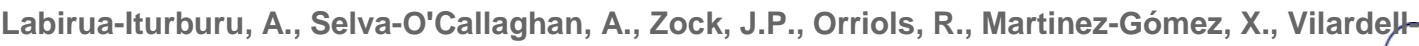
Tarrés, M. Occupational exposure in patients with the antisynthetase syndrome. Clinical Rheumatology: 2014, 33(2), 221-225

\begin{tabular}{|l|l|}
\hline $\begin{array}{l}\text { Postprint } \\
\text { Version }\end{array}$ & 1.0 \\
\hline Journal website & http://link.springer.com/article/10.1007/s10067-013-2467-0 \\
\hline Pubmed link & $\underline{\text { http://www.ncbi.nlm.nih.gov/pubmed/24384826 }}$ \\
\hline DOI & $10.1007 /$ s10067-013-2467-0 \\
\hline
\end{tabular}

This is a NIVEL certified Post Print, more info at http://www.nivel.eu

\title{
Occupational exposure in patients with the antisynthetase syndrome
}

Ane Labirua-ItUrburu ${ }^{1}$, Albert Selva-O’CALlaghan ${ }^{1}$, JAN-PAUl ZOCK ${ }^{2,3,4}$, RAMON ORRIOLS $^{5,7}$, XAVIER MARTÍNEZ-GÓMEZ ${ }^{6}$ AND MIQUEL VILARDELL-TARRÉS ${ }^{1}$

(1) Internal Medicine Department, Vall d'Hebrón General Hospital, Universitat Autónoma de Barcelona, C/Siracusa N ${ }^{\circ} 12$ Bis "A", Barcelona, 08012, Spain

(2) Centre for Research in Environmental Epidemiology (CREAL), Barcelona, Spain

(3) Hospital del Mar Medical Research Institute (IMIM), Barcelona, Spain

(4) CIBER Epidemiología y Salud Pública (CIBERESP), Barcelona, Spain

(5) Pneumology Service, Vall d'Hebron General Hospital, Barcelona, Spain

(6) Department of Preventive Medicine and Epidemiology, Vall d'Hebrón General Hospital, Barcelona, Spain

(7) CIBER de Enfermedades Respiratorias (CIBERES), Palma de Mallorca, Spain Albert Selva-O'Callaghan

Email: aselva@vhebron.net

\begin{abstract}
Interstitial lung disease (ILD) is common in patients with myositis and is related with the presence of antisynthetase autoantibodies (aSA). Together with other manifestations, the resulting condition is known as the antisynthetase syndrome (ASS). Contact with certain environmental and occupational agents is also associated with the development of ILD. The objective of this study was to analyze occupational exposure and associated clinical manifestations in a cohort of patients with ASS. aSA had been identified by line immunoassay and confirmed by immunoprecipitation. Serial pulmonary function tests had been carried out to assess lung function. Thirty-two ASS patients and a control group of 32 myositis patients without aSA underwent a specific questionnaire interview to evaluate their cumulative exposure to biological dust, mineral dust, and gases/fumes up to disease onset. Comparisons were done with the Fisher exact test and Mann-Whitney test. Out from 32 ASS patients (median age, 42.7 yeras; IQR 32.2-52.5), twenty-six patients had anti-Jo-1, three anti-PL-12, and three anti-PL-7. Nine had polymyositis, 15 dermatomyositis, one amyopathic dermatomyositis, and seven pure ILD without myositis. Sixteen ASS patients (50 \%) and seven (22 \%) myositis patients without aSA had ever been highly exposed to dust, gases, or fumes ( $\mathrm{p}<0.05$ ). A more than $10 \%$ improvement in forced vital capacity occurred in $61 \%$ of highly exposed patients and $23 \%$ of those with low/no exposure $(p=0.06)$ over the observation period. In
\end{abstract}


Labirua-Iturburu, A., Selva-O'Callaghan, A., Zock, J.P., Orriols, R., Martinez-Gómez, X., Vilarde佔 Tarrés, M. Occupational exposure in patients with the antisynthetase syndrome. Clinical Rheumatology: 2014, 33(2), 221-225

conclusion, a high percentage of patients with ASS had been exposed to dusts, gases, or fumes.

\section{INTRODUCTION}

Idiopathic inflammatory myopathies, such as dermatomyositis (DM) and polymyositis (PM) are systemic autoimmune diseases characterized by skeletal muscle inflammation. [1] Nearly half these patients have interstitial lung disease (ILD), which is related to the presence of a characteristic group of myositis-specific autoantibodies, the antisynthetase antibodies (aSA). [2, 3] Anti-histidyl-transfer RNA (tRNA) (anti-Jo-1) antibody, found in approximately 20 to $30 \%$ of PM and DM patients, is the most common of these autoantibodies. [4]

Lung involvement often coexists with, and sometimes precedes, the development of myositis. This temporal sequence raises the possibility that exposure to inhaled antigens could be a precipitating event that initiates an immune reaction in the lung and later involves muscle and other organs. [5] The presence of a proteolytically sensitive conformation of the histidyl-tRNA synthetase in the lung and data reported by some authors regarding the antisynthetase syndrome further supports this idea. [6-9]

Exposure to environmental agents and occupational dust has been related to the development of ILD. Several studies have reported an association between cryptogenic fibrosing alveolitis and occupational exposure to various agents, especially metal and wood dust but also cleaning products and paints, among others [10-16].

Our objective was to analyze the exposure to inhaled environmental or occupational agents in a cohort of patients with antisynthetase syndrome (ASS) and to examine clinical and immunological associations.

\section{PATIENTS AND METHODS}

\section{Patient population}

This is a cohort study with retrospectively collected data. Sixty patients positive for aSA were identified from a cohort of 179 adult patients with idiopathic inflammatory myopathies, seen at Vall d'Hebrón General Hospital in Barcelona (Spain) between 1983 and 2012. From this group, 32 patients were personally interviewed by one of the investigators with a specific questionnaire to assess lifetime occupational exposure to biological dust, mineral dust, and gases/fumes and were classified as having high exposure or no/low exposure. The other 28 cases were not included in the study for the following reasons: deceased (12 patients), lost to follow-up (12 patients), and refused participation in the study (4 patients). Six patients, three from each exposure group, were excluded from the lung function analysis because of insufficient data. A random sample of 32 myositis patients without aSA from our cohort of inflammatory myopathies was used as a control group. Controls were also personally interviewed, and the results were compared with those of ASS patients. Data on clinical and serologic features, pulmonary function testing, and therapies were obtained by review of the patients' medical records and laboratory databases. The clinical variables included the presence or absence of inflammatory myopathy, ILD, arthritis, Raynaud's phenomenon, mechanic's hands, fever, and a history of smoking. The diagnoses of DM and PM were based on the criteria of Bohan and 
Labirua-Iturburu, A., Selva-O'Callaghan, A., Zock, J.P., Orriols, R., Martinez-Gómez, X., Vilarde/h Tarrés, M. Occupational exposure in patients with the antisynthetase syndrome. Clinical Rheumatology: 2014, 33(2), 221-225

Peter [17], and only patients with definite or probable disease were included. The Sontheimer criteria [18] were used to diagnose amyopathic dermatomyositis (ADM). The diagnosis of ILD was established by high-resolution CT study. Spirometry was performed using a Datospir 200 (Sibel, Barcelona, Spain) according to the European Respiratory Society (ERS) guidelines [19]. The reference values used were those proposed by Roca et al. [20] for the Mediterranean population. Spirometry was performed in all patients at the time of the ILD diagnosis and during the course of the disease. An average of two tests were carried out per year. After the ILD diagnosis, avoidance of occupational exposure by inhalation was recommended. A consistent change in the forced vital capacity (FVC) of $10 \%$ in the absence of an alternate explanation was considered an improvement or progression of ILD. [21]

The study was approved by the Vall d'Hebron University Hospital Ethics Committee for Clinical Research [PR (AG) 112/2009], and all patients gave oral consent to the analysis and publication of their data.

\section{Determination of autoantibodies and HLA typing}

aSA were identified by ELISA or line immunoassay (Myositis Profile Euroline, Euroimmun, Lübeck, Germany) [22] and were confirmed by RNA or protein immunoprecipitation assay with radiolabeled HeLa cells [4]. HLA class II was detected with a sequence-specific primer and sequence-specific oligonucleotide polymerase chain reaction technique.

\section{Occupational exposure assessment}

Information on lifetime occupational history was obtained from the 32 patients and 32 controls using a structured interviewer-led questionnaire. The job title, type of industry, and starting and ending years were recorded for all jobs held for more than 12 consecutive months and at least $20 \mathrm{~h}$ per week. Jobs were coded using the Spanish version of the International Standard Classification of Occupations, 1988, (ISCO-88) system. [23] Job codes were linked to a general population job exposure matrix, [24, 25] classifying each individual job as associated with no, low, or high exposure to biological dust, mineral dust, or gases/fumes. Cumulative exposure to each of the three agents was determined using the total number of years the individual had worked in jobs with the assigned exposure until the onset of the disease. Comparisons between exposed and unexposed patients and between patients with ASS and the control group of myositis patients without aSA were performed using Fisher's exact test and the Mann-Whitney test. Significance was set at a p value of less than 0.05

\section{RESULTS}

Thirty-two patients (22 women) with ASS and ILD were interviewed. The median age was 42.7 years (Interquartile range (IQR) 32.2-52.5) (Table 1). The median time to the diagnosis of ILD in our sample was 1.6 months (IQR 0-29). Median follow-up after the ILD diagnosis was 61 months (IQR 32-120). Twenty-six patients tested positive for anti-Jo-1, three to anti-PL-12, and three to anti-PL-7. These patients were classified as having PM (9 cases), DM (15 cases), or ADM (1 case), and the remaining patients ( 7 cases) had pure ILD without myositis. Twenty-two patients (69 $\%)$ were carriers of the HLA-DRB1*03 haplotype. 
Labirua-Iturburu, A., Selva-O'Callaghan, A., Zock, J.P., Orriols, R., Martinez-Gómez, X., Vilarde/h Tarrés, M. Occupational exposure in patients with the antisynthetase syndrome. Clinical Rheumatology: 2014, 33(2), 221-225

\section{[TABLE 1]}

High occupational exposure to biological dust, mineral dust, or gases/fumes had occurred in 11, 10, and 13 patients, respectively (Table 2). Reported occupations are summarized in Table 3. Sixteen of the 32 ASS patients had ever been highly exposed to any of the three agents analyzed, whereas only seven from a random sample of 32 patients from our myositis cohort without aSA had such exposure (50\% vs $22 \%$; $\mathrm{p}<0.05)$. Other parameters, such as ILD $(\mathrm{p}<0.05)$, mechanic's hands $(\mathrm{p}<0.05)$, HLA-DRB $1 * 03(\mathrm{p}=0.05)$, and fever $(\mathrm{p}=0.06)$ were also more frequent in the ASS group, as would be expected (Table 1). ILD tended to be more common in patients with a history of high occupational exposure: 15 of 16 with ILD and high exposure versus 12 of 16 with ILD and no/low exposure (94\% vs. $75 \%$ ), although statistical significance was not reached $(\mathrm{p}=0.17)$. No association was found between the presence of pure ILD without myositis and exposure to any of the agents studied. No statistically significant differences were found in the severity of ILD, determined by FVC at onset, between patients with high or no/low exposure. No statistically significant association was found between the presence of arthritis, mechanic's hands, fever, Raynaud's phenomenon, type of myositis, positive status to HLADRB $1 * 03$ haplotype, or type of aSA and high exposure to any of the three agents. There were no statistically significant differences in the number of immunosuppressive drugs used between patients with high or no/low exposure. A consistent improvement of more than $10 \%$ in FVC during follow-up was observed in $61 \%$ of highly exposed patients (8 of 13) and only $23 \%$ (3 of 13) of those with no or low exposure $(\mathrm{p}=0.06)$ (Table 4$)$. Thus, in patients with a history of high exposure to dust, gases, or fumes, avoidance of exposure after the ILD diagnosis seemed to be associated with a better prognosis.

\section{[TABLE 2] [TABLE 3][TABLE 4]}

\section{DISCUSSION}

In this study, performed in a cohort of patients with ASS, we found that half the patients had been highly exposed to dust, fumes, or gases before the onset of the disease. ILD comprises a group of relatively rare lung conditions that involve varying degrees of acute and chronic inflammation that can progress to end-stage fibrosis. Environmental exposure to various agents, such as metal dust, wood dust, and dust containing steel, brass, lead, pine wood, or solvents, has been linked to an increased risk of developing pulmonary fibrosis. [9-16]

Several studies, mainly case reports, have described the development of rheumatic disease after different types of environmental exposures. A varied spectrum of clinical and serological autoimmune disorders, including scleroderma-like illnesses and lupus-like syndromes, has been reported after exposure to agents like solvents or silica. [26-30]

ASS-associated ILD is a heterogeneous entity that ranges from a benign stable disease to rapidly progressive and treatment-resistant pneumonitis [2] Lung involvement seems to be even more strongly associated with these autoantibodies than muscle, and ILD often precedes myositis symptoms. [3] These facts have led to hypotheses that the immune reaction starts in the lungs after exposure to certain 
Labirua-Iturburu, A., Selva-O'Callaghan, A., Zock, J.P., Orriols, R., Martinez-Gómez, X., Vilarde/th Tarrés, M. Occupational exposure in patients with the antisynthetase syndrome. Clinical Rheumatology: 2014, 33(2), 221-225

environmental factors, as in other interstitial pneumonias, and later spreads to other organs such as muscles and joints. [5] The finding of a more cleavable conformation of the hystidyl-tRNA synthetase enzyme in the lung, which makes it more antigenic, suggests that immunity may start in the lung. [6]

To date, there are no studies investigating the role of occupational exposure to inhaled agents in the pathogenesis of patients with ASS. The single related study from Tillie et al. [7] reported a high occupational exposure rate (39\%) in a cohort of 32 ASS patients with ILD, with $26 \%$ being employees in the cleaning industry. The authors suggested the possibility of exposure to abrasive agents as the triggering cause of pulmonary inflammation. According to an epidemiological research study carried out by Chinoy et al. [31] related to tobacco and ASS, there was a higher frequency of anti-Jo- 1 antibodies in patients who were positive for DRB $1 * 03$ and smokers, compared with DRB1*03-positive nonsmokers. Although the difference did not reach statistical significance, it suggests a gene-environment interaction in the development of anti-Jo-1 antibodies. Our results support this idea, since more than two thirds of the patients studied were positive for HLA-DRB $1 * 03$. In our report, $50 \%$ of patients diagnosed with ASS were highly exposed to biological dust, mineral dust, and/or gases and fumes, whereas only $22 \%$ of patients from our myositis cohort without aSA had such exposure. In any case, this figure is much higher than the $13 \%$ prevalence reported in a general population sample in our area. [32, 33] Moreover, when these highly exposed patients were compared with ASS patients with no or low exposure, a consistent improvement in FVC was observed. Avoidance of the offending agent after the ILD diagnosis could be a possible explanation. However, the retrospective nature of the study and the absence of reliable data that these patients systematically avoided exposure detract from these findings. Further studies are needed to clarify this issue.

There are several limitations to this study but also some strengths. The main limitations include the small patient sample due to the rarity of the syndrome, its retrospective nature, and possible recall bias in reporting the occupational history. The strengths of the study include the presence of a well-characterized comparison group and an external reference from a general population sample from the study area to compare the prevalence of exposure. In addition, the exposure assessment was based on established methods combining a structured face-to-face questionnaire on lifetime occupational history with a job exposure matrix. In summary, a high percentage of patients with ASS had been exposed to dusts, gases, or fumes before disease onset. These findings lend support to the idea that occupational exposure could play a role in the pathogenesis of some cases of ASS-associated ILD.

Acknowledgments

The authors are grateful to Hans Kromhout and Roel Vermeulen (IRAS, Utrecht University, The Netherlands) for use of their ALOHA job exposure matrix. We are also in debt to Luis Gallego for his kind assistance in interviewing the control patients.

Funding

This study was funded in part by a grant (FIS/2012 PI12-01320) from the Spanish Ministry of Health and Consumer Affairs.

\section{Disclosures}

None. 


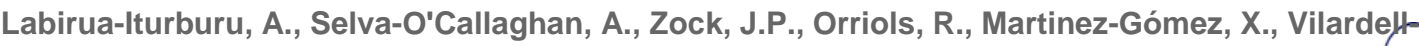
Tarrés, M. Occupational exposure in patients with the antisynthetase syndrome. Clinical Rheumatology: 2014, 33(2), 221-225

\section{REFERENCES}

1. Dalakas MC, Hohlfeld R (2003) Polymyositis and dermatomyositis. Lancet 362:971982PubMedCrossRef

2. Connors GR, Christopher-Stine L, Oddis CV, Danoff SK (2010) Interstitial lung disease associated with the idiopathic inflammatory myopathies. What progress has been made in the past 35 years? Chest 138:1464-1474PubMedCrossRef

3. Labirua A, Lundberg IE (2010) Interstitial lung disease and idiopathic inflammatory myopathies: progress and pitfalls. Curr Opin Rheumatol 22:633-638PubMedCrossRef

4. Selva-O'Callaghan A, Labrador-Horrillo M, Solans-Laque R, Simeon-Aznar CP, MartínezGómez X, Vilardell-Tarrés M (2006) Myositis-specific and myositis-associated antibodies in a series of eighty-eight Mediterranean patients with idiopathic inflammatory myopathy. Arthritis Rheum 55:791-798PubMedCrossRef

5. Lundberg IE, Grundtman C (2008) Developments in the scientific and clinical understanding of inflammatory myopathies. Arthritis Res Ther 10:220PubMedCentralPubMedCrossRef

6. Levine SM, Raben N, Xie D, Askin FB, Tuder R, Mullins M et al (2007) Novel conformation of histidyl-transfer RNA synthetase in the lung: the target tissue in Jo-1 autoantibodyassociated myositis. Arthritis Rheum 56:2729-2739PubMedCrossRef

7. Tillie-Leblond I, Wislez M, Valeyre D, Crestani B, Rabbat A, Israel-Biet D et al (2008) Interstitial lung disease and anti-Jo-1 antibodies: difference between acute and gradual onset. Thorax 63:53-59PubMedCrossRef

8. Labirua-Iturburu A, Selva-O'Callaghan A et al. (2012) Anti-PL-7 (anti-threonyl-tRNA synthetase) antisynthetase syndrome: clinical manifestations in a series of patients from a European multicenter study (EUMYONET) and review of the literature. Medicine (Baltimore) (in press)

9. Serratrice J, Granel B, Pache X et al (2001) A case of polymyositis with anti-histidyl-t-RNA synthetase (Jo-1) antibody syndrome following extensive vinyl chloride exposure. Clin Rheumatol 20:379-382PubMedCrossRef

10. Scott J, Johnston I, Britton J (1990) What causes fibrosing alveolitis? A case-control study of environmental exposure to dust. BMJ 301:1015-1017PubMedCrossRef

11. Iwai K, Mori T, Yamada N, Yamaguchi M, Hosoda Y (1994) Idiopathic pulmonary fibrosis. Epidemiologic approaches to occupational exposure. Am J Respir Crit Care Med 150:670675PubMedCrossRef

12. Moya C, Anot JM, Newman-Taylor AJ (1994) Outbreak of organising pneumonia in textile printing sprayers. Lancet 344:498-452PubMedCrossRef

13. Hubbard L, Lewis S, Richards K, Johnston I, Britton J (1996) Occupational exposure to metal or wood dust and aetiology of cryptogenic fibrosing alveolitis. Lancet 347:284289PubMedCrossRef

14. Baumgartner KB, Samet JM et.al. (1997) Occupational and environmental risk factors for idiopathic pulmonary fibrosis: a multicenter case control study. Am J Epidemiol 145: s61

15. Hubbard R, Cooper M, Antoniak M et al (2000) Risk of cryptogenic fibrosing alveolitis in metal workers. Lancet 355:466-467PubMed

16. Hubbard R (2001) Occupational dust exposure and the aetiology of cryptogenic fibrosing alveolitis. Eur Respir J 18(Suppl 32):119s-121s

17. Bohan A, Peter JB (1975) Polymyositis and dermatomyositis. N Engl J Med 292(3447):403-407PubMedCrossRef

18. Sontheimer RD (1999) Cutaneous features of classic dermatomyositis and amyopathic dermatomyositis. Curr Opin Rheumatol 11:475-482PubMedCrossRef

19. Quanjer PH, Tammeling GJ, Cotes JE, Pedersen OF, Peslin R, Yernault JC (1993) Lung volumes and forced ventilatory flows. Report Working Party Standardization of Lung Function Tests, European Community for Steel and Coal. Official Statement of the European Respiratory Society. Eur Respir J 16:5-40

20. Roca J, Sanchis J, Agusti-Vidal A, Segarra F, Navajas D, Rodriguez-Roisin R et al (1986) Spirometric reference values from a Mediterranean population. Bull Eur Physiopathol Respir 22:217-224PubMed 


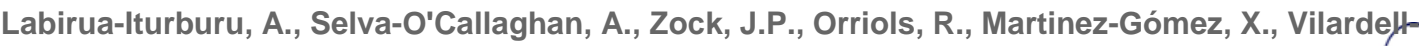
Tarrés, M. Occupational exposure in patients with the antisynthetase syndrome. Clinical Rheumatology: 2014, 33(2), 221-225

21. Raghu G, Collard HR, Egan JJ, Martinez FJ, Behr J, Brown KK et al (2011) An official ATS/ERS/JRS/ALAT statement: idiopathic pulmonary fibrosis: evidence-based guidelines for diagnosis and management. Am J Respir Crit Care Med 183:788-824PubMedCrossRef 22. Ghirardello A, Rampudda M, Ekholm L, Bassi N, Tarricone E, Zampieri S et al (2010) Diagnostic performance and validation of autoantibody testing in myositis by a commercial line blot assay. Rheumatology (Oxford) 49:2370-2374CrossRef

23. International Labour Office (1991) International Standard Classification of Occupations: ISCO 88. ILO: Geneva

24. Matheson MC, Benke G, Raven J, Sim MR, Kromhout H, Vermeulen R, Johns DP, Walters EH, Abramson MJ (2005) Biological dust exposure in the workplace is a risk factor for chronic obstructive pulmonary disease. Thorax 60:645-651PubMedCrossRef

25. Sunyer J, Zock JP, Kromhout H, Garcia-Esteban R, Radon K, Jarvis D, Toren K, Künzli N, Norbäck D, d'Errico A, Urrutia I, Payo F, Olivieri M, Villani S, van Sprundel M, Antó JM, Kogevinas M (2005) Lung function decline, chronic bronchitis and occupational exposures in young adults. Am J Respir Crit Care Med 172:1139-1145PubMedCrossRef

26. Miller FW, Hess EV, Clauw DJ et al (2000) Approaches for identifying and defining environmentally associated rheumatic disorders. Arthritis Rheum 43:343-349

27. Mayes MD (1999) Epidemiologic studies of environmental agents and systemic autoimmune diseases. Environ Health Perspect 107(Suppl 5):743748PubMedCentralPubMedCrossRef

28. Selva-O'Callaghan A, Tura JM, Grau-Junyent JM, Labrador-Horrillo M, Solans-Laque R, Vilardell-Tarrés M (2004) Silicone gel filled breast implants and dermatomyositis. Clin Exp Rheumatol 22:376PubMed

29. Slimani S, Ben Ammar A, Ladjouze-Rezig A (2010) Connective tissue diseases after heavy exposure to silica: a report of nine cases in stonemasons. Clin Rheumatol 29:531533PubMedCrossRef

30. Sanchez-Roman J, Wichmann I, Salaberri J, Varela JM, Nuñez-Roldan A (1993) Multiple clinical and biological autoimmune manifestations in 50 workers after occupational exposure to silica. Ann Rheum Dis 52:534-538PubMedCrossRef

31. Chinoy H, Adimulam S, Marriage F, New P, Vincze M, Zilahi E, Kapitány A, Gyetvai A, Ekholm L, Novota P, Remakova M, Charles P, McHugh NJ, Padyukov L, Alfredsson L, Vencovsky J, Lundberg IE, Danko K, Ollier WE, Cooper RG (2012) Interaction of HLADRB ${ }^{\star} 03$ and smoking for the development of anti-Jo-1 antibodies in adult idiopathic inflammatory myopathies: a European-wide case study. Ann Rheum Dis 71:961965PubMedCentralPubMedCrossRef

32. Zock JP, Cavallé N, Kromhout H, Kennedy SM, Sunyer J, Jaén A, Muniozguren N, Payo F, Almar E, Sánchez JL, Antó JM, Kogevinas M (2004) Evaluation of specific occupational asthma risks in a community-based study with special reference to single and multiple exposures. J Expo Anal Environ Epidemiol 14:397-403PubMedCrossRef

33. Sunyer J, Kogevinas M, Kromhout H, Antó JM, Roca J, Tobias A, Vermeulen R, Payo F, Maldonado JA, Martinez-Moratalla J, Muniozguren N (1998) Pulmonary ventilatory defects and occupational exposures in a population-based study in Spain. Am J Respir Crit Care Med 157:512-517 


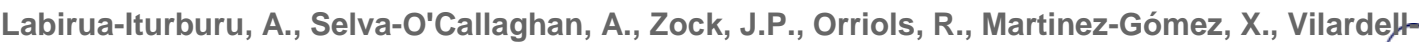
Tarrés, M. Occupational exposure in patients with the antisynthetase syndrome. Clinical

\section{TABLES AND FIGURES}

Table 1

Clinical characteristics and epidemiological data of the cohort of patients with antisynthetase syndrome and the control group

\begin{tabular}{|l|l|l|l|}
\hline & $\begin{array}{l}\text { Cases } \\
(\mathbf{n = 3 2})\end{array}$ & $\begin{array}{l}\text { Controls } \\
(\mathbf{n = 3 2})\end{array}$ & p \\
\hline Female gender & $22(69)$ & $27(84)$ & 0.16 \\
\hline Median age at symptoms onset, years (IQR) & $\begin{array}{l}42.7(32.2- \\
52.5)\end{array}$ & $\begin{array}{l}44.1(32.2- \\
52.6)\end{array}$ & 0.84 \\
\hline $\begin{array}{l}\text { Median time working to clinical } \\
\text { manifestations, years (IQR) }\end{array}$ & $\begin{array}{l}20.2(8.5- \\
35.6)\end{array}$ & $\begin{array}{l}13.2(8.0- \\
31.2)\end{array}$ & 0.20 \\
\hline Any job with high exposure ${ }^{\mathrm{a}}$ & $16(50)$ & $7(22)$ & $<0.05^{*}$ \\
\hline Smoking & $19(59.4)$ & DU & - \\
\hline Interstitial lung disease myositis ${ }^{\mathrm{b}}$ & $27(84.4)$ & $7(22)$ & $<0.05$ \\
\hline Dermatomyositis & $15(46.8)$ & $23(71)$ & 0.05 \\
\hline Polymyositis & $9(28.1)$ & $7(22)$ & 0.6 \\
\hline Amyopathic dermatomyositis & $1(3.1)$ & $1(3.1)$ & - \\
\hline Fever & $9(28.1)$ & $3(1)$ & 0.06 \\
\hline Raynaud's phenomenon & $15(46.8)$ & $9(28)$ & 0.13 \\
\hline Mechanic's hands & $18(56.2)$ & $4(12.5)$ & $<0.05$ \\
\hline HLA-DRB1*03 & $22(68.7)$ & $14(43)$ & 0.05 \\
\hline
\end{tabular}

Data are expressed as number (\%), unless otherwise indicated

IQR interquartile range, DU data unavailable

*Statistically significant. ( $p=0.04$ after gender adjustment)

${ }^{a}$ Occupational exposure to dust, gases, or fumes

${ }^{\mathrm{b}}$ Seven patients had pure interstitial lung disease without myositis

\section{Table 2}

Descriptive statistics of lifetime occupational exposure up to clinical appearance, $\mathrm{n}$ (\%)

\begin{tabular}{|l|l|l|l|}
\hline Variables & No exposure & Low exposure & High exposure \\
\hline Biological dust & $12(37.5)$ & $9(28.1)$ & $11(34.4)$ \\
\hline Mineral dust & $14(43.7)$ & $8(25)$ & $10(31.3)$ \\
\hline Gases and fumes & $12(37.5)$ & $7(21.9)$ & $13(40.6)$ \\
\hline Dusts, gases, and/or fumes & $9(28.1)$ & $7(21.9)$ & $16(50)$ \\
\hline
\end{tabular}

Duration of exposure until appearance of first symptoms ranged from 1 to 52 years 


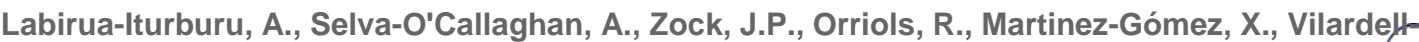
Tarrés, M. Occupational exposure in patients with the antisynthetase syndrome. Clinical

Table 3

Most frequently reported occupations, $\mathrm{n}(\%)$

\begin{tabular}{|l|l|}
\hline $\begin{array}{l}\text { Complete occupational history } \\
\text { (included 91 different jobs) [32 } \\
\text { patients] }\end{array}$ & $\begin{array}{l}\text { Ever high exposure to dusts, gases and/or } \\
\text { fumes (Included 29 different jobs) [16 } \\
\text { patients] }\end{array}$ \\
\hline Administrative, 17 (19) & Agricultural workers, 9 (31) \\
\hline Agricultural workers, 9 (10) & Chemical products machine operators, 4 (14) \\
\hline Manufacturing workers, 9 (10) & Construction workers, 2 (7) \\
\hline Cleaners and related, 8 (9) & Machinery mechanics and fitters, 2 (7) \\
\hline Managers, 5 (5) & $\begin{array}{l}\text { Food and related products machine } \\
\text { operators, 2 (7) }\end{array}$ \\
\hline Textile workers, 4 (4) & Other, 10 (34) \\
\hline Other, 39 (43) & \\
\hline
\end{tabular}

Table 4

Associations between lifetime occupational exposure and clinical characteristics, $n$ $(\%)$

\begin{tabular}{|l|l|l|l|}
\hline Clinical characteristics & $\begin{array}{l}\text { Exposed* } \\
\text { (n= 16) }\end{array}$ & $\begin{array}{l}\text { Nonexposed } \\
\text { (n= 16) }\end{array}$ & $\begin{array}{l}\text { Statistical } \\
\text { significance (p) }\end{array}$ \\
\hline ILD & $15(94)$ & $12(75)$ & 0.17 \\
\hline Arthritis & $15(94)$ & $14(87)$ & 0.50 \\
\hline Myositis & $12(75)$ & $13(81)$ & 0.50 \\
\hline Fever & $4(25)$ & $5(30)$ & 0.50 \\
\hline $\begin{array}{l}\text { Mechanic's hands } 10 \\
\text { (62) }\end{array}$ & $10(62)$ & $8(50)$ & 0.36 \\
\hline \begin{tabular}{l|l|l|} 
FVC improvement \\
(>10\%)
\end{tabular} & $8(61)$ & $3(23)$ & 0.06 \\
\hline Raynaud's phenomenon & $7(44)$ & $8(50)$ & 0.50 \\
\hline HLA-DRB1*03 & $10(62)$ & $12(75)$ & 0.36 \\
\hline
\end{tabular}

FVC forced vital capacity

*Ever worked in a job involving high exposure to dusts, gases, or fumes. p value obtained using Fisher's exact test

${ }^{\#}$ Percentage is calculated after excluding 3 patients in each group bacause of insufficient data 